\title{
Virtual Teaching/Learning Relationships
}

\author{
Lynne Anderson, John Cartafalsa \\ National University, USA
}

\begin{abstract}
The authors studied factors that impact relationships in both virtual and face-to-face teaching/learning settings. Their studies examined relationships of students with instructor, instructor with students, and students with students. Both graduate and undergraduate students participated in the studies. Relationships in the authors' studies were more specifically described as student-tostudent interactions, student-to-instructor interactions, and instructor-to-student interactions. How does interactivity vary between on campus (face to face) teaching/learning settings and online (virtual) teaching/learning settings? Implications for online teaching may be clarified.
\end{abstract}

\section{Introduction}

In the twenty-first century, online teaching/learning has been capturing the imagination and the market of students on all levels of learning all around the world. Studies that compare face-toface teaching/learning settings to the virtual classroom have tended to focus upon student satisfaction or performance measures. Differences within the two settings, while obvious, have not been linked to performance measures. The authors hypothesize that performance measures can be linked to teaching/learning interactivity and differences therein between on campus (face-to-face) and online (virtual) settings. The authors completed two studies: 1. an on campus (face to face) desired teaching/learning relationships, and 2. a replicated study in online (virtual) classrooms both within their university of employment. Comparisons between the two studies were made and will be shared.

\section{Body of Knowledge}

The authors originally studied factors that impact relationships in on campus (face to face) teaching/learning settings. This study examined desired relationships of students with instructor, instructor with students, and students with students. Through qualitative analysis of narratives of what students and faculty wanted from their teaching/learning experience, three themes describing those desired relationships emerged. Graduate and undergraduate students and faculty members participated in the original study from all schools within the university at the time.

Theme One: Teaching/Learning Environment illustrated student desires for open, non-threatening, enjoyable and respectful attitudes in student-faculty relationships.

Theme Two: Exchange of Information illustrated student desires to learn from the instructor and from one another, and to interact with one another more than with the instructor.

Theme Three: Mentor/Peer Association illustrated student desire for developing networks among students to help with coursework, job-seeking, and become friends; whereas, faculty desired principles of effective teaching to help students learn [1][2].

In the twenty-first century, Apple announces the i-Pad and online teaching/learning captures an increasing market share on all levels of learning all around the world. In learning academies research about the brain and its involvement in disease and learning soars as technology advances. Psychologists and educators are learning about learning and thinking. Bandura, a renowned pioneer in social learning theory, began with this supposition: learning from interactions among three factors: personal characteristics, behavioral patterns, and social environment, such as, interactions with others [3]. Bandura elaborated that the three factors influence one another and to what degree he did not ascertain [3].

The authors initial study took one of the factors of social environment, as described by Bandura, as interactions with others, implying its importance in any teaching/learning environment [3]. Bandura used interactions; the authors use relationships in the teaching/learning community. Relationships in the authors' studies were more specifically described as student to student interactions, student to instructor interactions, and instructor to student interactions. If relationships play an important role in on campus (face to face) teaching/learning settings, it stands that online teaching/learning settings hold a similar relational value.

Teaching/learning relationships in the on campus (face to face) study has been replicated by the authors in the online teaching/learning setting. As the online study replicated the same methodology and inquired using the same survey questions of both 
graduates and undergraduate students as the initial study, the authors were able to compare interactivity in teaching/learning settings.

\section{Interactivity in Learning}

Online teaching has been able to promote high degrees of interactivity within a technologically mainstream environment. Following Bandura's supposition, high levels of interaction which promote social engagement can have positive effects on the learning experience. Woods and Baker [6] suggested that failing to consider the relational dynamics in the online setting may produce greater social isolation among distance learners, reduced levels of student satisfaction, poor levels of student satisfaction, poor academic performance, and increased attrition.

Younger, more technologically alert, students were more comfortable with interactivity in the online learning setting according to Garcia and Qin [4]. Further Garcia and Qin online learners expected to interact with the content and to synthesize with various online resources over listening to a lecture. Both younger and older students agreed that university-level course content is effectively done through discussions with the instructor and with fellow students. Interactivity was an effective way to learn according to Garcia and Qin.

Roper surveyed graduate students who earned their degrees by taking 80 percent or more of their courses exclusively online. Fifty-nine student responses (with GPAs of at least 3.50) responded. Roper combined responses by identifying seven tips for online learners. The second most frequently mentioned value of online coursework was online discussions. Seventh on the list was making connections with fellow students [5].

\section{Findings}

Findings in the authors' initial study centered about attributes of interaction/relationships in on campus (face to face) learning settings. Respect, mentoring, friendship, networking were frequently mentioned in students narratives. These attributes support the Social Learning Theory formally presented by Bandura. In their study of interaction/relationships online (virtual) learning setting, the authors learned that the same attributes appeared in student narratives. Predominant, however, in the online setting was the addition of a strong, common response from student online learners, that is, responsiveness. Students agreed that response rate was an important factor in interaction/relationships in an online learning setting. Immediacy of that response rate was deemed of value by all participants in the authors' study of online learning settings. Response rate was not mentioned by a single student in the on campus study.

The authors in both of their studies found interactivity desired by students and faculty alike in learning/teaching settings. In the on campus (face to face) setting, students preferred interaction with fellow students to with the instructor. In the online (virtual) setting, students preferred interaction to have immediacy, that is, a rapid response rate. Convincingly, interaction in both face to face and virtual learning settings is desired for effective learning. In the face to face learning setting interaction among students was deemed of special value; and, in the online learning setting, immediacy of response rate was deemed of special value....albeit student or instructor.

\section{References}

[1] Anderson, L.E. and J.S. Cartafalsa (1996). Reshaping faculty interaction: peer-mentoring groups. Journal of Staff, Program, and Organization Development. 14(2), 7177.

[2] Anderson, L.E. and J.S. Cartafalsa. (2002). Factors that make faculty and student relationships effective, The College Teacher, 50(4):134-8.

[3] Beihler, R.F. and J. Snowman (11th Ed.) (2006). Psychology Application to Teaching. Boston: HoughtonMifflin Co.

[4] Garcia, Paul and Jingjing Qin. 2007. Identifying the generation gap in higher education: where do the differences lie? Innovate: 3 (4).

[5] Roper Alan R. How students develop online learning skills: Good ideas.

http://www.educause.edu/EDUCAUSE+Quarterly/EDUC AUSEQuarterlyMagazineVolum/HowStudentsDevelopOnl ineLearni/157435.

[6] Woods, Jr., Robert H.and Jason D. Baker. Interaction and Immediacy in Online Learning. International Review of Research in Open and Distance Learning 5(2): August, 2004 